\title{
In vitro response to EPA, DPA, and DHA: Comparison of effects on ruminal fermentation and biohydrogenation of 18-carbon fatty acids in cows and ewes
}

\author{
P. G. Toral, ${ }^{* 1}$ G. Hervás, ${ }^{*}$ D. Carreño, ${ }^{*}$ H. Leskinen, $†$ A. Belenguer, ${ }^{*}$ K. J. Shingfield, $\ddagger^{2}$ and P. Frutos ${ }^{*}$ \\ *Instituto de Ganadería de Montaña, CSIC-Universidad de León, Finca Marzanas s/n, 24346 Grulleros, Leon, Spain \\ †Green Technology, Nutritional Physiology, Natural Resources Institute Finland (LUKE), FI-31600 Jokioinen, Finland \\ łInstitute of Biological, Environmental and Rural Sciences, Animal and Microbial Sciences, Aberystwyth University, Aberystwyth, \\ Ceredigion SY23 3EB, United Kingdom
}

\begin{abstract}
The modulation of milk fat nutritional quality through fish oil supplementation seems to be largely explained by the action of $n-3$ very long chain polyunsaturated fatty acids (PUFA) on ruminal biohydrogenation $(\mathrm{BH})$ of C18 fatty acids (FA). However, relationships among this action, disappearance of those PUFA in the rumen, and potential detrimental consequences on ruminal fermentation remain uncertain. This study compared the effect of 20:5n-3 (eicosapentaenoic acid; EPA), 22:5n-3 (docosapentaenoic acid; DPA), and 22:6n-3 (docosahexaenoic acid; DHA) on rumen fermentation and $\mathrm{BH}$ of $\mathrm{C} 18 \mathrm{FA}$ and was conducted simultaneously in cows and sheep to provide novel insights into interspecies differences. The trial was performed in vitro using batch cultures of rumen microorganisms with inocula collected from cannulated cows and ewes. The PUFA were added at a dose of $2 \%$ incubated dry matter, and treatment effects on ruminal C18 FA concentrations, PUFA disappearances, and fermentation parameters (gas production, ammonia and volatile FA concentrations, and dry matter and neutral detergent fiber disappearances) were examined after $24 \mathrm{~h}$ of incubation. A principal component analysis suggested that responses to PUFA treatments explained most of the variability; those of ruminant species were of lower relevance. Overall, EPA and DHA were equally effective for inhibiting the saturation of trans-11 18:1 to 18:0 and had a similar influence on ruminal fermentation in cows and sheep (e.g., reductions in gas production and acetate:propionate ratio). Nevertheless, DHA further promoted alternative BH pathways that lead to trans-10 18:1 accumulation, and EPA seemed to have specific effects on 18:3n-3 me-
\end{abstract}

\footnotetext{
Received January 24, 2017.

Accepted April 21, 2017.

${ }^{1}$ Corresponding author: pablo.toral@csic.es

${ }^{2}$ Deceased.
}

tabolism. Only minor variations attributable to DPA were observed in the studied parameters, suggesting a low contribution of this FA to the action of marine lipids. Although most changes due to the added PUFA were comparable in bovine and ovine, there were also relevant specificities, such as a stronger inhibition of 18:0 formation in cows and a greater increase in 18:3n-3 metabolites in sheep. No direct relationship between in vitro disappearance of the incubated PUFA and effect on $\mathrm{BH}$ (in particular, inhibition of the last step) was found in either cows or ewes, calling into question a putative link between extent of disappearance and toxicity for microbiota. Conversely, an association between the influence of these PUFA on ruminal lipid metabolism and fermentation may exist in both species. In vivo verification of these findings would be advisable.

Key words: cattle, polyunsaturated fatty acid, ruminal lipid metabolism, sheep, trans fatty acid

\section{INTRODUCTION}

Some marine lipid supplements (e.g., tuna and sardine oil or Schizochytrium microalgae) have been tested as sources of eicosapentaenoic acid (EPA; 20:5n-3) and docosahexaenoic acid (DHA; 22:6n-3) for dairy ruminants, but transfer rates into milk of both PUFA are limited by extensive ruminal disappearances (Loor et al., 2005; Shingfield et al., 2012). For this reason, research on their use in ruminant feeding has mainly focused on their role as modulators of the last biohydrogenation (BH) step of 18-carbon fatty acids (FA; Boeckaert et al., 2008b; Toral et al., 2010b) with the aim of increasing the outflow of trans-11 18:1 that serves as a substrate for mammary cis-9,trans-11 CLA synthesis (Bernard et al., 2013).

Docosahexaenoic acid is supposed to be a stronger inhibitor of ruminal trans 18:1 saturation than EPA (AbuGhazaleh and Jenkins, 2004), but this latter PUFA is more extensively metabolized in the rumen than the former (Gulati et al., 1999; Dohme et al., 2003), which 
might be related to a more toxic effect of EPA for rumen microbiota (Maia et al., 2007). Nonetheless, the relationship among the disappearance of these PUFA in the rumen, inhibition of the last step of unsaturated C18 FA BH, and potential detrimental effects on ruminal fermentation (Fievez et al., 2003; Lee et al., 2005; Toral et al., 2009) is still uncertain.

Although EPA and DHA are accepted to be the main FA responsible for the effects of fish oil and some marine microalgae on $\mathrm{BH}$, the contribution of less abundant C20 and C22 PUFA remains largely unknown (AbuGhazaleh et al., 2006). For example, we are not aware of published data regarding docosapentaenoic acid (DPA; 22:5n-3). The proportion of DPA in fish oil represents only approximately 5 to $15 \%$ of the sum of EPA and DHA (Fievez et al., 2003; Kim et al., 2008; Toral et al., 2010b), but its transfer efficiency from diet into milk is several-fold higher than that of EPA and DHA, which often results in similar or even greater DPA concentrations in milk fat (Offer et al., 1999; Kairenius et al., 2015; Toral et al., 2016b). The cause of these differences in PUFA apparent transfer rates is as yet unknown but might derive from low DPA disappearance in the rumen (Kim et al., 2008; Shingfield et al., 2012), which in turn might suggest a less negative effect on microbiota, or from DPA accumulation as a putative intermediate of ruminal DHA metabolism (Kairenius et al., 2011; Toral et al., 2012).

Despite the well-known differences in the rumen FA metabolism between cattle and small ruminants fed plant lipids (Shingfield et al., 2013), it has been suggested that differences would not be so clear when it comes to marine oils (Or-Rashid et al., 2008; Toral et al., 2012) because their effects on rumen and milk FA profiles have been consistently observed in cows, ewes, and goats (e.g., Boeckaert et al., 2008a; Toral et al., $2015,2016 \mathrm{~b}$ ). However, a direct comparison of ruminal responses to fish oil supplementation in cows and goats reports more pronounced changes in $\mathrm{BH}$ in the caprine (Toral et al., 2016a), which points again to interspecies variations. We are not aware of any comparative study with sheep that has been published so far. On this basis, we conducted an in vitro experiment with the aims of investigating the effects of EPA, DPA, and DHA on the $\mathrm{BH}$ of dietary 18-carbon FA and on ruminal fermentation and comparing responses of cows and ewes.

\section{MATERIALS AND METHODS}

All experimental procedures were approved and completed in accordance with the Spanish Royal Decree $53 / 2013$ for the protection of animals used for experimental purposes.
Table 1. Formulation and chemical composition of the experimental diet

\begin{tabular}{lc}
\hline Item & TMR \\
\hline Ingredient, g/kg of fresh matter & \\
Dehydrated alfalfa hay (particle size $>4 \mathrm{~cm}$ ) & 500 \\
Whole corn grain & 140 \\
Whole barley grain & 100 \\
Soybean meal solvent $44 \% \mathrm{CP}$ & 150 \\
Sugar beet pulp (pellets) & 50 \\
Molasses (liquid) $^{1}$ & 40 \\
Mineral supplement $^{2}$ & 18 \\
Vitamin supplement & 2 \\
Chemical composition, $\mathrm{g} / \mathrm{kg}$ of DM & \\
OM & 900 \\
CP & 187 \\
NDF & 311 \\
ADF & 218 \\
Total fatty acids & 17.65 \\
16:0 & 4.22 \\
18:0 & 0.93 \\
cis-9 18:1 & 2.29 \\
18:2n-6 & 6.23 \\
18:3n-3 & 2.39 \\
\hline
\end{tabular}

${ }^{1}$ Declared as containing (g/kg) $\mathrm{CaCO}_{3}(556), \mathrm{Ca}_{2} \mathrm{HPO}_{4}$ (222), and $\mathrm{NaCl}(222)$.

${ }^{2}$ Vitafac Ovino $0.2 \%$ AC (DSM Nutritional Products SA, Madrid, Spain). Declared as containing vitamin A $(4,000,000 \mathrm{IU} / \mathrm{kg})$, vitamin $\mathrm{D}_{3}(1,000,000 \mathrm{IU} / \mathrm{kg})$, vitamin E $(5 \mathrm{~g} / \mathrm{kg}), \mathrm{Fe}(17.5 \mathrm{~g} / \mathrm{kg}), \mathrm{Mn}(20 \mathrm{~g} /$ $\mathrm{kg})$, Co $(50 \mathrm{mg} / \mathrm{kg})$, I $(250 \mathrm{mg} / \mathrm{kg}), \mathrm{Zn}(15 \mathrm{~g} / \mathrm{kg})$, Se $(100 \mathrm{mg} / \mathrm{kg})$, sepiolite $(100 \mathrm{~g} / \mathrm{kg})$, Ca $(26.2 \mathrm{~g} / \mathrm{kg})$, and $\mathrm{Mg}(6.15 \mathrm{~g} / \mathrm{kg})$.

\section{Batch Cultures of Rumen Microorganisms}

This trial was conducted in vitro following a $2 \times$ 4 factorial arrangement: 2 species (ovine and bovine) and 4 treatments (EPA, DPA, and DHA, and a control without FA). Batch cultures of rumen microorganisms were conducted as outlined previously (Frutos et al., 2004). Rumen fluid was collected from 2 ewes (BW = $76 \pm 8.4 \mathrm{~kg})$ and 2 cows $(\mathrm{BW}=727 \pm 77.5 \mathrm{~kg})$, each equipped with a ruminal cannula of 4 and $10 \mathrm{~cm}$ i.d., respectively. Animals were individually penned and fed a TMR (see Table 1 for ingredients) in 2 daily meals $(60 \%$ at $0900 \mathrm{~h}$ and $40 \%$ at $1700 \mathrm{~h})$. The offer was fixed to their estimated maintenance energy requirements (INRA, 2007) to work under similar conditions in both species. Clean drinking water was always available.

After an adaptation period of $15 \mathrm{~d}$, rumen inocula were obtained via the cannula before the morning feeding. The inocula were immediately taken in thermal flasks to the laboratory, where they were strained through a nylon membrane $(400 \mu \mathrm{m}$; Fisher Scientific S.L., Madrid, Spain) while being bubbled with $\mathrm{CO}_{2}$. For each species, equal volumes of the 2 strained rumen fluids were combined and mixed (1:4) with phosphatebicarbonate buffer (Goering and Van Soest, 1970). The incubation was repeated on 3 consecutive days (replicates) using 16-mL Hungate tubes for the BH study and 
125 -mL sealed serum flasks for the fermentation study, which contained 12 and $50 \mathrm{~mL}$ of buffered rumen fluid, respectively. The TMR fed to the animals was used as the substrate for incubation $(10 \mathrm{mg} / \mathrm{mL}$ of buffered rumen fluid) and was ground in a hammer mill fitted with a 0.5- or 1-mm screen for the Hungate tubes or serum flasks, respectively. Both vials were incubated under anaerobic conditions for $24 \mathrm{~h}$ in an incubator set at $39.5^{\circ} \mathrm{C}$. Blanks containing buffered rumen fluid without substrate were incubated under the same conditions.

Each PUFA [10-2005-9 (EPA), 10-2205-9 (DPA), and 10-2206-9 (DHA); Larodan, Solna, Sweden] was dissolved in ethanol $96 \%$ at $0.5 \%$ of the incubation volume, as it has been shown that such concentration of ethanol would not impair fermentation (Morgavi et al., 2004), and was dispersed with an ultrasonic device (UP200H, Hielscher Ultrasonics GmbH, Teltow, Germany). The dose of each PUFA was $200 \mu \mathrm{g} / \mathrm{mL}$ of buffered rumen fluid (which is equivalent to $2 \% \mathrm{DM}$ of the substrate) and was added into the tubes and flasks just before the incubation started. The control treatment and blanks were dosed only the corresponding amount of ethanol.

\section{Measurements and Samplings}

Representative samples of the TMR were collected, stored at $-30^{\circ} \mathrm{C}$, and then freeze dried before chemical analysis.

$\boldsymbol{B H}$ Study. After $24 \mathrm{~h}$ of incubation, the reaction was stopped by placing the Hungate tubes into ice water for approximately $5 \mathrm{~min}$. They were then stored at $-80^{\circ} \mathrm{C}$ until FA analysis.

Fermentation Study. The extent of gas production was determined by measuring head-space gas pressure at 6,12 , and $24 \mathrm{~h}$ postinoculation. Pressure values, corrected for the quantity of $\mathrm{OM}$ incubated and gas released from the blanks, were used to generate gas volume estimates using a predictive equation (Hervás et al., 2005). After $24 \mathrm{~h}$ of incubation, the reaction was stopped by placing the flasks into ice water for approximately 10 to $15 \mathrm{~min}$. Centrifuged samples (at 976 $\times g$ for $10 \mathrm{~min}$ ) were collected for ammonia and VFA determinations and stored at $-30^{\circ} \mathrm{C}$ until analysis. Values of DM and NDF disappearance were estimated by filtering the residues using preweighed sintered glass crucibles (100-160 $\mu \mathrm{m}$; Pyrex, Stone, UK), correcting with blanks, and determining the NDF content, as reported in Frutos et al. (2004).

\section{Chemical Analysis}

Diet samples were prepared and analyzed for chemical composition (DM, ash, $\mathrm{CP}, \mathrm{NDF}$, and $\mathrm{ADF}$ ) as detailed in Toral et al. (2016b). Fatty acid methyl esters of lipid in $200 \mathrm{mg}$ of freeze-dried TMR samples were prepared in duplicate following a 1-step extraction-transesterification procedure (Shingfield et al., 2003) and adding 1 mg of cis-12 13:1 (10-1301-9, Larodan) as an internal standard. Methyl esters were separated and quantified by GC as explained below for ruminal digesta samples. Peak identification was based on retention time comparisons with commercially available standard FAME mixtures (Nu-Chek Prep, Elysian, MN; Sigma-Aldrich, Madrid, Spain).

Samples for ruminal FA composition were freeze dried directly in the Hungate tubes. Immediately before extraction, $1 \mathrm{mg}$ of internal standard (cis-12 13:1, Larodan) was added to each tube, which contained approximately $200 \mathrm{mg}$ of freeze-dried digesta. The lipids were then extracted twice, and the organic extracts were combined and converted to FAME by sequential base-acid catalyzed transesterification (Toral et al., 2010b). Methyl esters were separated and quantified with a gas chromatograph (7890A GC System, Agilent, Santa Clara, CA) equipped with a flame ionization detector and a 100-m fused silica capillary column (CPSIL 88, CP7489, Varian Ibérica S.A., Madrid, Spain) and hydrogen as the carrier gas. Total FAME profile was determined using a temperature gradient program and then isothermal conditions at $170^{\circ} \mathrm{C}$ to further resolve 18:1 isomers (Shingfield et al., 2003). Peaks were identified based on retention time comparisons with the same FAME mixtures used for the analysis of feeds, other commercially available standards (Nu-Chek Prep and Larodan), cross-referencing with chromatograms reported in the literature, and comparison with selected ruminal digesta samples for which the FA composition was determined based on GC and GC-MS analysis of corresponding 4,4-dimethyloxazoline derivatives (Toral et al., 2010b; Kairenius et al., 2011). For details, refer to Toral et al. (2010b, 2016b). The FAME were converted to FA using theoretical relative response factors for GC analysis (Wolff et al., 1995). The C18 FA in the ruminal digesta were then expressed as a percentage of total FA, whereas those in TMR samples and EPA, DPA, and DHA in ruminal digesta were quantified using the cis-12 13:1 internal standard, which has been shown to improve the accuracy of this type of analysis (Jenkins, 2010). Disappearance of the 3 incubated n-3 PUFA was calculated considering the amount initially added to the Hungate tubes; control samples were devoid of EPA, DPA, and DHA in both ruminant species. The ammonia concentration was determined by colorimetry and VFA was determined by GC using crotonic acid as the internal standard in centrifuged samples (Frutos et al., 2004). 


\section{Statistical Analysis}

The relationship between in vitro ruminal C18 FA concentrations, disappearances of the incubated PUFA and fermentation parameters was assessed through a principal component analysis (PCA) using the R-project software (http://www.r-project.org, version 3.2.3). Statistical analyses were also performed using the SAS software package (version 9.4; SAS Institute Inc., Cary, NC). Ruminal C18 FA concentrations and fermentation parameters were analyzed by ANOVA to test the fixed effects of PUFA treatments (control, EPA, DPA and DHA), species (bovine and ovine), and their interaction. Disappearances of incubated PUFA in the rumen were also analyzed by ANOVA to test the fixed effect of PUFA type (EPA, DPA and DHA), species, and their interaction. In both cases, the incubation run and the inoculum nested within the species were designated as random effects. Means were separated through the pairwise differences ("pdiff") option of the least squares means ("lsmeans") statement of the MIXED procedure, and adjusted for multiple comparisons using Bonferroni's method. Differences were declared significant at $P<0.05$ and considered a trend toward significance at $0.05 \leq P<0.10$. Least squares means are reported.

\section{RESULTS}

\section{PCA}

The PCA discriminated 2 principal components (PC) that described $35.0 \%$ (PC1) and $18.6 \%$ (PC2) of the variation in ruminal $\mathrm{BH}$ and fermentation and $1 \mathrm{PC}$ that accounted for $9.1 \%$ of total variability (PC3). The score plot (Figure 1a) showed that PC1 separated 2 major groups based on PUFA treatment; samples from EPA and DHA incubations were mostly in the positive range, whereas those from the control and DPA incubations were largely in the negative range. Additionally, PC2 clearly discriminated based on ruminant species; ewes were positioned in the positive ranges and cows were positioned in the negative ranges. Within each species, the EPA and DHA samples clustered together and distant from their controls, and those from the DPA treatment were mostly found in intermediate positions closer to the control in sheep.

The loading plot (Figure 1b) showed that the concentration of 18:0 was negatively correlated with PC1 and was loaded near 18:3n-3 and the molar proportion of acetate and opposite the major cluster including propionate and some 18:1 and 18:2 isomers (e.g., cis-9, cis- 11 , trans- 9 , and trans-10 18:1; trans- 9 ,trans- 12 , cis9,trans-12, and trans-11,cis-15 18:2). On the other hand, the concentrations of trans-16 and cis-16 18:1, trans12,cis-15 18:2, trans 18:3, and ammonia were positively correlated with $\mathrm{PC} 2$, whereas 13- and 16-oxo-18:0 were negatively correlated with this PC. The in vitro disappearance of the 3 incubated PUFA and the concentrations of 9- and 15-oxo-18:0 or cis-9,trans-11 CLA and NDF and DM disappearances were positioned close to the origin of the plot, with no apparent relationship with any of the main PC.

\section{Ruminal BH}

Concentrations of identified 18-carbon FA in the in vitro ruminal digesta of cows and ewes are shown in Table 2. For reasons of clarity, Supplemental Table S1 (https://doi.org/10.3168/jds.2017-12638) reports the main effects for species and PUFA treatments in those parameters for which the level of significance of the interaction was $P>0.05$.

Both species showed a similar amount of 18:0 in the control (on average $55 \%$ of total FA). This FA was negatively affected by the 3 PUFA treatments $(P<$ 0.05; Supplemental Table S1, https://doi.org/10.3168/ jds.2017-12638), and effects tended to be different in bovine and ovine (interaction species $\times$ PUFA; $P<$ 0.10 ; Table 2). Thus, the extent of the decrease in 18:0 was comparable with the 3 PUFA in cattle (a mean of $-37 \%$ compared with the control) but not in sheep, where decreases were slightly less pronounced (on average $-27 \%$ relative to the control) and there were differences between DHA and DPA.

Five other saturated C18 FA were also detected in the digesta samples. In general, the concentrations of 10-, 13-, and 16-oxo-18:0 were greater in cattle $(P<$ $0.05)$ and affected by treatments only in this species; the 3 PUFA reduced the accumulation of 13- and 16oxo-18:0 $(P<0.05)$, and EPA increased 10-oxo-18:0 $(P$ $<0.05$; Table 2). On the other hand, the low concentrations of 15-oxo-18:0 (coeluting with an unidentified FA) in cows and ewes were only modified by DPA $(P<$ 0.05; Supplemental Table S1, https://doi.org/10.3168/ jds.2017-12638), which constitutes an exception to the overall effects of this PUFA on ruminal metabolites (i.e., the effects are generally similar or less pronounced than respective changes with EPA or DHA).

Incubations with DHA favored the accumulation of cis-9 18:1 and trans-5 18:1 in bovine and ovine $(P$ $<$ 0.05; Table 2; Supplemental Table S1, https://doi. org/10.3168/jds.2017-12638). On the contrary, PUFAinduced changes in other cis- and trans-18:1 isomers usually interacted with the species $(P<0.05)$. For example, increments in the concentration of trans-11 18:1 in cows were greater in EPA and DHA treatments 

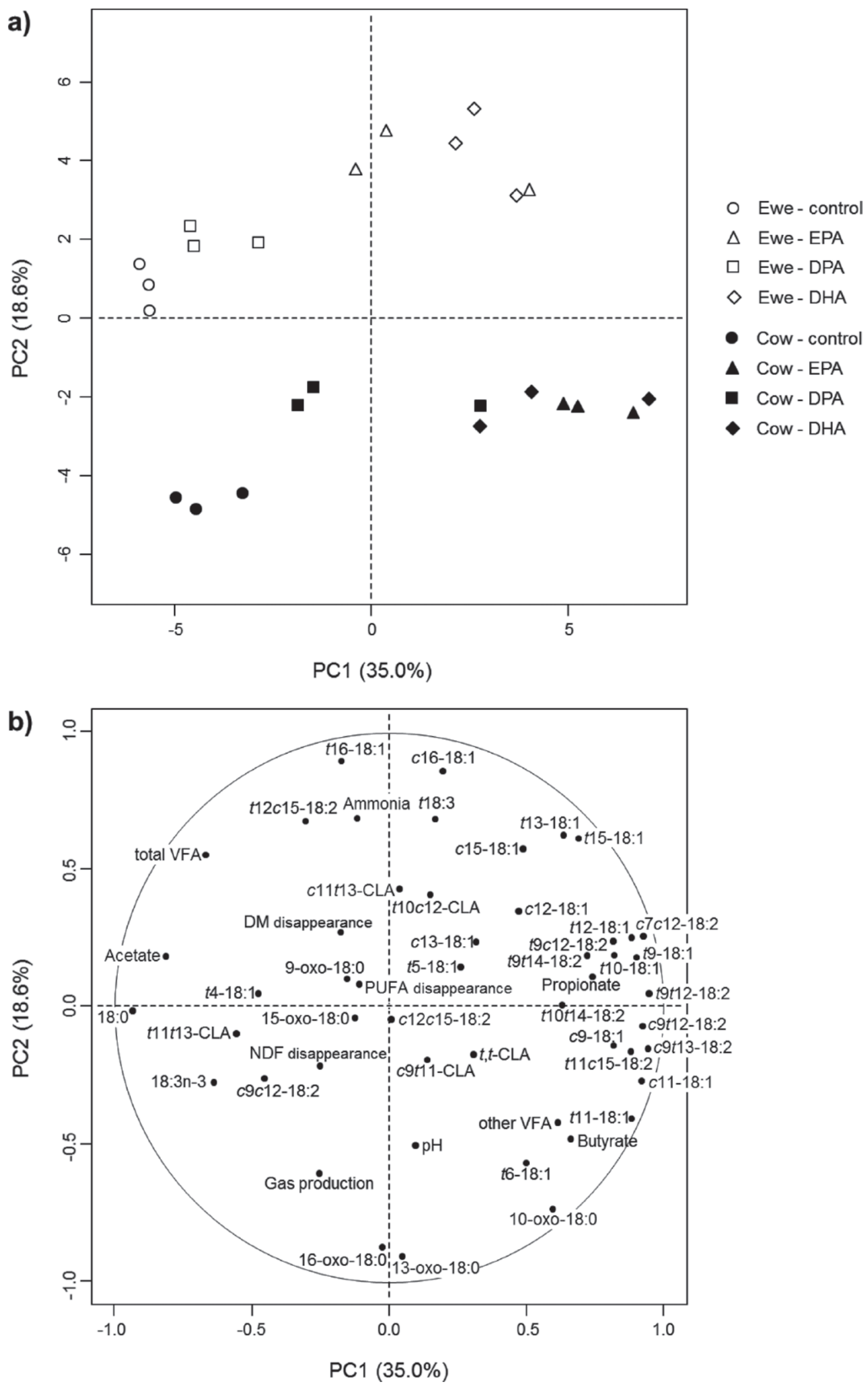

Figure 1. Principal component analysis of ruminal biohydrogenation metabolites and fermentation parameters after $24 \mathrm{~h}$ of in vitro incubation with rumen inocula from cows or ewes. (a) Score plot and (b) loading plot projected on the basis of the 2 principal components (PC1 and PC2). The incubated substrate was a TMR containing no additional PUFA (control) or supplemented with $2 \%$ DM of eicosapentaenoic acid (EPA), docosapentaenoic acid (DPA), or docosahexaenoic acid (DHA). $t=$ trans; $c=$ cis. 
(a mean of $79 \%$ compared with the control) than in DPA treatments (35\%), whereas DHA was the only PUFA that improved the accumulation of this FA in ewes $(64 \% ; P<0.05)$. Other increments in minor 18:1 isomers, such as those induced by EPA and DHA on cis-16 and trans-15 and 16 18:1, were significant or more pronounced in sheep $(P<0.05)$. Regarding trans-10 18:1, DHA led to the greatest increase in both species $(262 \%$ compared with controls; $P<0.05)$, but DPA affected it only in bovine (to a similar extent as DHA) and EPA in ovine cultures (150\%; $P<0.05)$. Furthermore, EPA and DHA but not DPA increased the proportion of cis-11 18:1 $(P<0.05$; Supplemental Table S1, https://doi.org/10.3168/jds.2017-12638).

As mentioned previously, the effects of DPA on C18 FA concentrations were generally less marked than those of EPA or DHA. This observation was particularly evident for 18:2 isomers because DPA modified only 18:2n-6 and trans-12,cis-15 18:2 $(P<0.05$; Supplemental Table S1, https://doi.org/10.3168/jds.2017-12638). Reductions in 18:2n-6 were also significant in cows on EPA and DHA $(P<0.05)$ as well as accumulation of some 18:2 metabolites in both species (e.g., cis-9,trans-12, trans-10,trans-14, and trans-9,trans-12 18:2; $P<0.05)$. Incubations with EPA showed the greatest concentrations of trans-11,cis-15 18:2 and trans-9,trans-14 18:2 $(P<0.05$; Table 2; Supplemental Table S1, https:// doi.org/10.3168/jds.2017-12638), but no significant response to PUFA was detected in the accumulation of the major CLA isomer (i.e., cis-9,trans-11 18:2; $P>0.10$ ), and the tendency in the antilipogenic trans-10,cis-12 CLA disappeared after Bonferroni adjustment.

Few 18:3 isomers were detected in the ruminal digesta, and their concentrations were low (Table 2). The 18:3n-3 was affected by PUFA only in cows (on average $-69 \%$ compared with the control; $P<0.05$ ), and the unresolved peak including 2 minor 18:3 intermediates (i.e., trans- 9 ,trans- 12, cis- 15 and cis-9,cis-12,trans- 15 18:3) was affected by EPA only in sheep $(P<0.05)$.

Finally, in vitro ruminal disappearances of the 3 very long chain PUFA were very high after $24 \mathrm{~h}$ of incubation in both cows (first value of the following pairs) and ewes (last value), with mean data of $96 \pm 1.0$ and 97 $\pm 0.6 \%$ for EPA, $92 \pm 0.6$ and $94 \pm 0.3$ for DPA, and $75 \pm 13.8$ and $83 \% \pm 8.1$ for DHA. Values were significantly lower for DHA $(P<0.05)$, but no differences due to the ruminant species were detected $(P>0.10)$.

\section{Ruminal Fermentation}

Reductions in gas production and total VFA concentration (on average -7 and $-9 \%$, respectively) were observed in EPA and DHA incubations $(P<0.05$; Table 3; Supplemental Table S1, https://doi.org/10.3168/

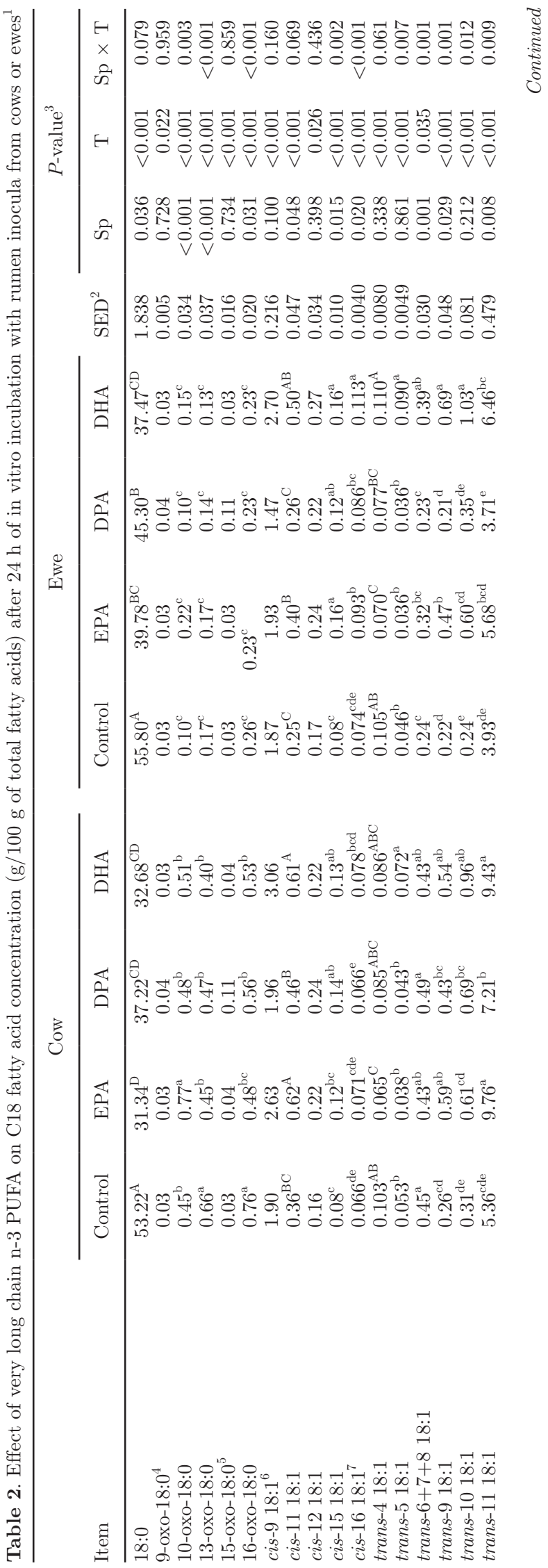




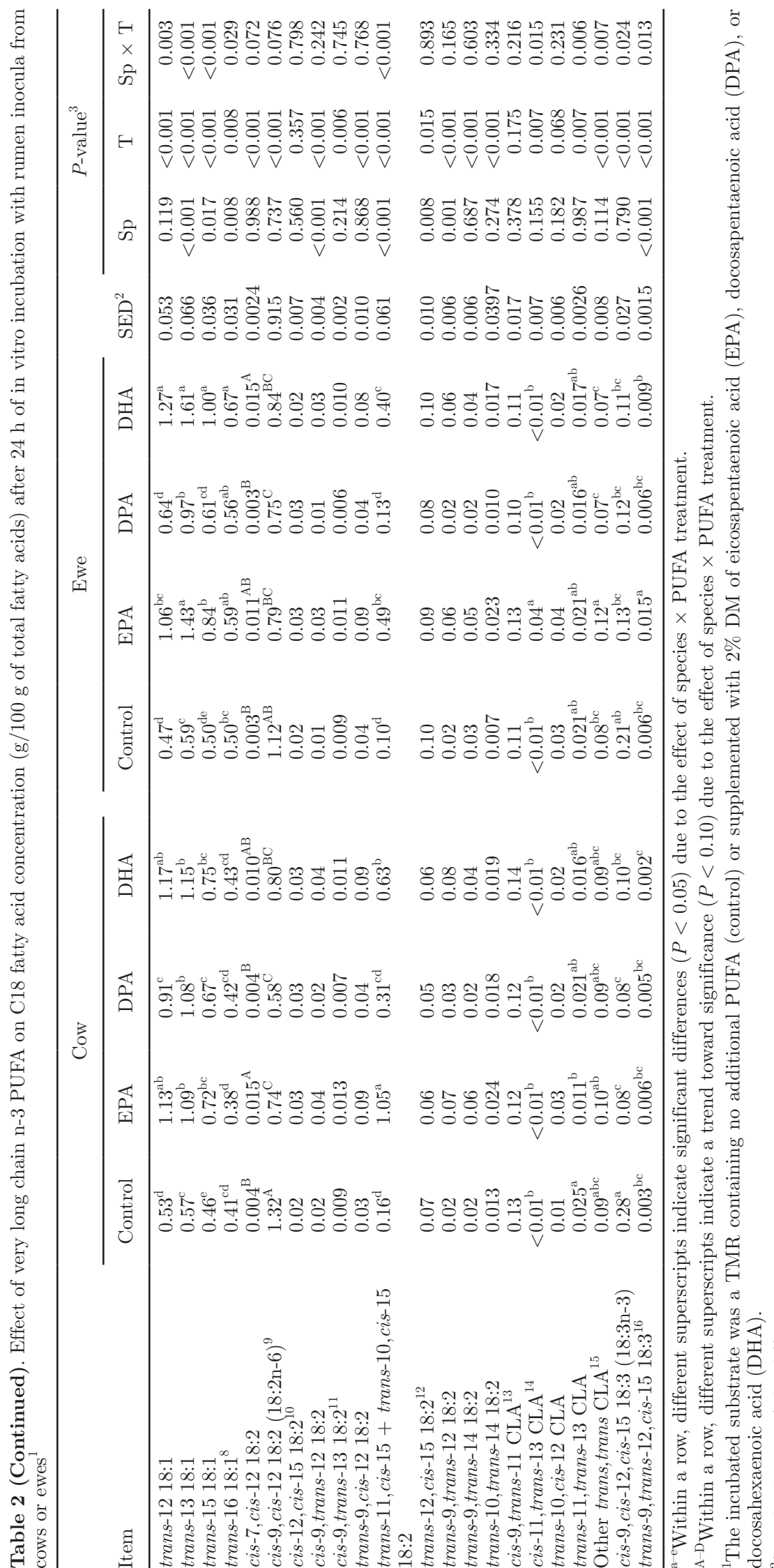

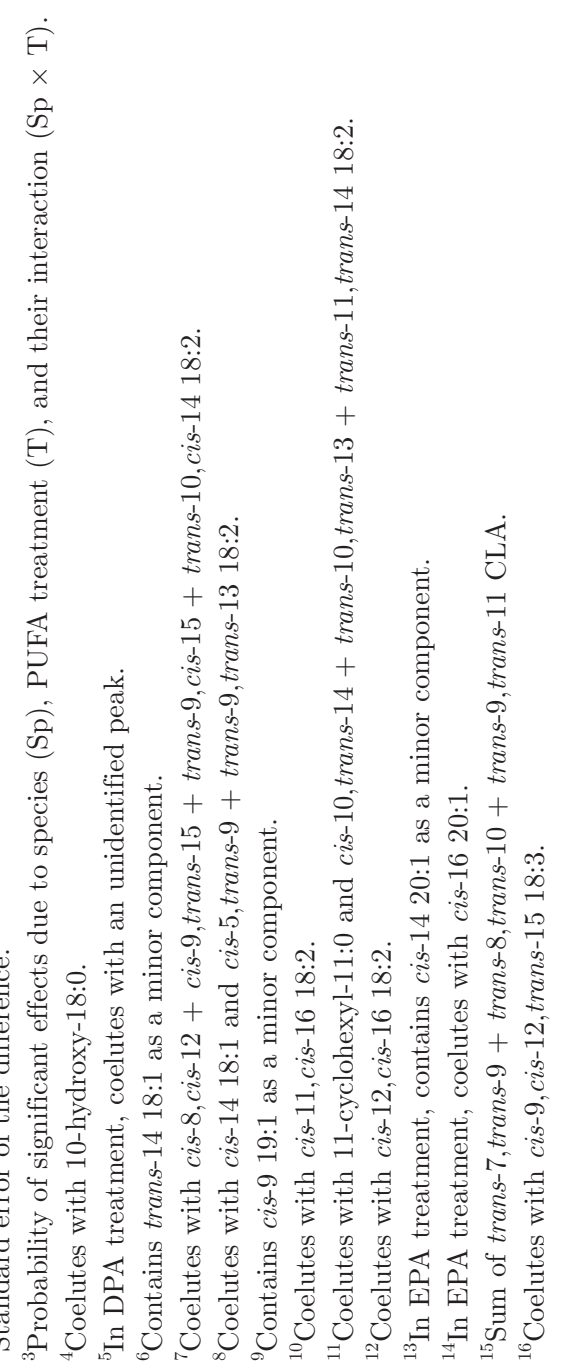


Table 3. Effect of very long chain n-3 PUFA on ruminal fermentation parameters after $24 \mathrm{~h}$ of in vitro incubation with rumen inocula from cows or ewes ${ }^{1}$

\begin{tabular}{|c|c|c|c|c|c|c|c|c|c|c|c|c|}
\hline \multirow[b]{2}{*}{ Item } & \multicolumn{4}{|c|}{ Cow } & \multicolumn{4}{|c|}{ Ewe } & \multirow[b]{2}{*}{$\mathrm{SED}^{2}$} & \multicolumn{3}{|c|}{$P$-value ${ }^{3}$} \\
\hline & Control & EPA & DPA & DHA & Control & EPA & DPA & DHA & & $\mathrm{Sp}$ & $\mathrm{T}$ & $\begin{array}{c}\mathrm{Sp} \times \\
\mathrm{T}\end{array}$ \\
\hline NDF disappearance, $\mathrm{g} / \mathrm{g}$ & 0.23 & 0.16 & 0.23 & 0.11 & 0.15 & 0.18 & 0.17 & 0.15 & 0.043 & 0.523 & 0.086 & 0.080 \\
\hline Gas production, $\mathrm{mL} / \mathrm{g}$ of $\mathrm{OM}$ & $231.5^{\mathrm{A}}$ & $208.3^{\mathrm{B}}$ & $221.8^{\mathrm{AB}}$ & $217.3^{\mathrm{AB}}$ & $213.9^{\mathrm{AB}}$ & $207.0^{\mathrm{AB}}$ & $210.3^{\mathrm{AB}}$ & $199.4^{\mathrm{AB}}$ & 10.61 & 0.290 & 0.001 & 0.068 \\
\hline Ammonia, $\mathrm{mg} / \mathrm{L}$ & 470.2 & 482.8 & 499.3 & 525.3 & 574.6 & 603.6 & 555.3 & 612.9 & 45.06 & 0.056 & 0.243 & 0.575 \\
\hline $\begin{array}{l}\text { Molar proportion, mol/mol } \\
\text { Acetate }\end{array}$ & $0.62^{\mathrm{AB}}$ & $0.56^{\mathrm{CD}}$ & $0.61^{\mathrm{AB}}$ & $0.56^{\mathrm{D}}$ & $0.64^{\mathrm{A}}$ & $0.61^{\mathrm{B}}$ & $0.62^{\mathrm{AB}}$ & $0.60^{\mathrm{BC}}$ & 0.010 & 0.047 & $<0.001$ & 0.077 \\
\hline Propionate & 0.16 & 0.20 & 0.17 & 0.20 & 0.16 & 0.19 & 0.17 & 0.19 & 0.065 & 0.672 & $<0.001$ & 0.468 \\
\hline Butyrate & 0.16 & 0.17 & 0.16 & 0.18 & 0.14 & 0.15 & 0.15 & 0.15 & 0.048 & 0.021 & 0.003 & 0.141 \\
\hline Others $^{4}$ & $0.059^{\mathrm{b}}$ & $0.069^{\mathrm{a}}$ & $0.061^{\mathrm{b}}$ & $0.070^{\mathrm{a}}$ & $0.058^{\mathrm{b}}$ & $0.057^{\mathrm{b}}$ & $0.056^{\mathrm{b}}$ & $0.061^{\mathrm{ab}}$ & 0.0029 & 0.062 & $<0.001$ & 0.002 \\
\hline Acetate:propionate ratio & 3.85 & 2.89 & 3.61 & 2.84 & 3.97 & 3.26 & 3.61 & 3.15 & 0.191 & 0.306 & $<0.001$ & 0.280 \\
\hline
\end{tabular}

${ }^{a, b}$ Within a row, different superscripts indicate significant differences $(P<0.05)$ due to the effect of species $\times$ PUFA treatment.

${ }^{\mathrm{A}-\mathrm{D}}$ Within a row, different superscripts indicate a trend toward significance $(P<0.10)$ due to the effect of species $\times$ PUFA treatment.

${ }^{1}$ The incubated substrate was a TMR containing no additional PUFA (control) or supplemented with $2 \%$ DM of eicosapentaenoic acid (EPA), docosapentaenoic acid (DPA), or docosahexaenoic acid (DHA).

${ }^{2}$ Standard error of the difference.

${ }^{3}$ Probability of significant effects due to species (Sp), PUFA treatment $(\mathrm{T})$, and their interaction $(\mathrm{Sp} \times \mathrm{T})$.

${ }^{4}$ Calculated as the sum of isobutyrate, isovalerate, valerate, and caproate.

jds.2017-12638). On the contrary, neither DM nor NDF disappearances varied significantly because of PUFA treatments or species $(P>0.10$ for all pairwise comparisons after Bonferroni adjustment). Ammonia concentrations and $\mathrm{pH}$ were not affected by PUFA either $(P>0.10)$, but ammonia tended to be higher (on average $19 \%)$ in ewes $(P<0.10)$.

Total VFA were higher $(P<0.05)$ in ewes. Regarding VFA molar proportions, DPA had discernible effects only on propionate, whereas EPA and DHA decreased acetate and increased propionate and butyrate $(P<$ 0.05). The PUFA-induced reductions in acetate tended to be slightly greater in cows $(P<0.10)$, but effects on the acetate:propionate ratio were similar in both species.

\section{DISCUSSION}

The interest in modulating the nutritional quality of milk fat has encouraged research on the mechanisms mediating the effects of supplementation with marine lipids rich in very long chain n-3 PUFA, which seem to be largely explained by changes in the ruminal environment (Loor et al., 2005; Toral et al., 2012). This study provides a comparison of the effect of EPA, DPA, and DHA on the ruminal BH of dietary FA and fermentation and was conducted simultaneously in cows and sheep to provide novel insights into interspecies differences.
The PCA was very helpful for describing the main trends in results. The response to PUFA treatment (related to PC1) explained the major part of the variability, and that of ruminant species (associated with PC2) was of lower relevance (Figure 1a). In the loading plot (Figure 1b), some of the most important $\mathrm{BH}$ and fermentation parameters were aligned with PC1 (e.g., 18:0 and acetate in the negative range; major 18:1 and 18:2 intermediates and propionate in the positive range), whereas those found in greater concentrations in ovine digesta were positively correlated with $\mathrm{PC} 2$ (e.g., minor metabolites of 18:3n-3 and ammonia) and placed in the area opposite some FA that were more abundant in bovine (e.g., 13- and 16-oxo-18:0). Although care is needed when extrapolating in vitro results to in vivo conditions, the general outcome of PCA is consistent with indirect comparisons between cows and ewes fed fish oil and PUFA-rich microalgae (e.g., Or-Rashid et al., 2008; Toral et al., 2012), suggesting less pronounced interspecies differences than those due to feeding highconcentrate diets and plant oils (Shingfield et al., 2013). Further in vivo comparative studies would be advisable to confirm this finding.

Marine lipids with high contents of C20 and C22 PUFA have often been used to inhibit the saturation of trans-11 18:1 with the final goal of enhancing milk cis9,trans-11 CLA (Loor et al., 2005; Toral et al., 2010a). In this regard, similar changes in trans-11 18:1 and 18:0 in EPA and DHA treatments suggest that both FA 
may be equally effective for meeting this objective and, therefore, supplements containing differing EPA:DHA ratios (e.g., fish oils or marine algae) would have comparable effects at the same PUFA dose. This contrasts with the greater concentrations of trans-11 18:1 and cis-9,trans-11 CLA reported by Vahmani et al. (2013) in the milk of cows receiving DHA-rich algae compared with EPA-rich fish oil, possibly due to the presence of other bioactive compounds in marine algae. However, our results suggest that the contribution of DPA to trans-11 18:1 accumulation would be minor, and that of 20:3n-3 and 22:3n-3 was ruled out in a previous study (AbuGhazaleh et al., 2006). An alternative explanation might lay on the form of fat supplements. They were added as free FA in our trial, whereas those used by Vahmani et al. (2013) were protected from ruminal metabolism, and Stamey et al. (2012) reported that at a similar DHA dose, protected algae were more effective at inhibiting the last $\mathrm{BH}$ step than extracted algal oil.

AbuGhazaleh and Jenkins (2004) suggested a stronger inhibitory effect of DHA than EPA on in vitro trans 18:1 hydrogenation, but no individual isomers were reported in their work. In our case, the higher trans 18:1 accumulation with DHA is mainly accounted for by the greatest concentrations of trans-10 18:1 and trans-5 18:1 in both species and by trans- 9 , trans-12, and trans- 15 in ovine, all deriving from alternative $\mathrm{BH}$ pathways. This would be in line with the different effect of DHA and EPA on the growth of some ruminal bacteria (Maia et al., 2007) and might have implications for animal performance due to the putative yet controversial antilipogenic activity of trans-10 18:1 (Lock et al., 2007; Kadegowda et al., 2009). Nevertheless, compared with DHA, EPA induced similar or even larger increases in the accumulation of other metabolites that have been associated with fish oil-induced milk fat depression (MFD) in cows and ewes (Kairenius et al., 2015; Toral et al., 2015, 2016b), specifically cis-11 18:1, 10-oxo-18:0, and, probably, trans-10, cis-15 18:2 (which coeluted with trans-11,cis-15 18:2 under our chromatographic conditions). The DPA had no effects on these candidate milk fat inhibitors. As expected, trans-10,cis-12 CLA, the only FA unequivocally shown to decrease mammary lipogenesis (Harvatine et al., 2009), was not affected by treatment, which is consistent with the small to negligible changes in its concentration in the digesta and milk of cows and ewes fed marine lipids rich in very long chain n-3 PUFA (Lee et al., 2005; Boeckaert et al., 2008a; Toral et al., 2012).

Notwithstanding the above, there were also interspecies differences in the effects of PUFA that may have practical implications. For example, variations in 18:0 and trans-11 18:1 after the addition of EPA, DPA, or DHA suggest that under the same basal diet and dose of lipids, the rumen microbiota of cows would be more sensitive than that of ewes to supplements rich in C20 and C22 PUFA. This might be related to the severity of marine lipid-induced MFD in each species because, in the absence of direct in vivo comparisons between lactating animals, greater decreases in milk fat concentration have been observed in bovines (upper range of 37-54\%; Boeckaert et al., 2008a; Alizadeh et al., 2012) than in ovines (up to 31\%; Toral et al., 2010a; Carreño et al., 2016). However, increases in some minor metabolites (e.g., trans-13, trans-16, and cis-16 18:1; cis-11,trans-13 18:2; and trans-9,trans-12,trans-15 and cis-9,cis-12,trans-15 18:3) were greater in sheep, suggesting that some alternative $\mathrm{BH}$ pathways would have been more favored in this species. A similar inference was obtained when comparing ruminal responses of goats and cows to fish oil supply (Toral et al., 2016a). Given the low responsiveness of small ruminants to other milk fat-depressing conditions (e.g., feeding high-starch diets and plant lipids; Shingfield et al., 2013), this would merit further research to determine whether the promotion of these alternative $\mathrm{BH}$ pathways may actually be related to the development of fish oil-induced MFD in sheep and goats (Toral et al., 2015, 2016b).

Increases in cis-9, cis-11, and cis-16 18:1 support that not only trans $18: 1$ but also cis $18: 1$ saturation was limited by very long chain n-3 PUFA (AbuGhazaleh and Jenkins, 2004; Boeckaert et al., 2008b). Similarly, 18:2 and 18:3 hydrogenation might have been constrained, in particular by EPA, which induced the greatest trans-11,cis-15 18:2, trans-9,trans-14 18:2, and trans-9,trans-12,cis-15 18:3 accumulation. All these isomers may derive from 18:3n-3 metabolism (Shingfield et al., 2013), suggesting a specific effect of EPA on the microbiota involved in this process. These results would not be explained by a general slowdown of its ruminal metabolism because 18:3n-3 was also decreased. Concerning DPA, in general the responses in 18:2 and 18:3 metabolites to this FA were marginal, reinforcing its putative minor role in explaining the effects of marine lipids.

Surprisingly, PUFA-induced variation in 18:2 concentrations was not accompanied by relevant differences in CLA isomers. A low and stable percentage of cis-9,trans-11 CLA was found in both species, which contrasts with the greater increase in the accumulation of its precursor for mammary $\Delta^{9}$-desaturation (trans-11 18:1). This supports the idea that interspecies differences in the magnitude of milk rumenic acid enrichments to C20 and C22 PUFA supply would be independent of ruminal CLA flow and explained by postruminal FA metabolism (Loor et al., 2005; Reynolds et al., 2006; Carreño et al., 2016). 
According to changes in oxo-FA concentrations, ruminal hydration (an alternative metabolic pathway to $\mathrm{BH}$ ) would have also been affected by PUFA treatments, with species-specific responses consistent with differences in hydrating bacteria in the rumen of cattle and sheep (Hudson et al., 2000). A putative link between keto-FA and marine lipid-induced MFD has been proposed based on the increases in 10-oxo-18:0 percentage in the digesta and milk of cows and ewes receiving fish oil (Kairenius et al., 2015; Toral et al., 2015, 2016b) and the bioactivity of other oxylipids derived from dietary FA (Raphael et al., 2014). The most abundant keto-FA was 16-oxo-18:0, as reported in the rumen of cows (Katz and Keeney, 1966), which is rarely quantified in the digesta, probably because of its elution at the end of the chromatogram.

Overall, changes in 18-carbon intermediate metabolites showed no clear association with differences in the in vitro disappearance of the 3 incubated PUFA, which would call into question a putative relationship between the latter parameter and potentially toxic effects of these PUFA on rumen microorganisms (Dohme et al., 2003; Maia et al., 2007; Lourenço et al., 2010). The in vitro disappearance was more extensive for EPA than for DHA, consistent with previous investigations (Gulati et al., 1999; Dohme et al., 2003; AbuGhazaleh and Jenkins, 2004), but the reasons explaining this finding and the greater variability observed for DHA in our trial remain uncertain. Earlier in vitro studies reported a very wide range of C20 and C22 PUFA disappearances (from $\sim 10 \%$ to almost $100 \%$ ), which appear to be related to large differences in PUFA dose and inoculum amount (Gulati et al., 1999; AbuGhazaleh and Jenkins, 2004; Vlaeminck et al., 2014). Our results would be on the upper part of this range, in agreement with most in vivo trials in cows and sheep (Shingfield et al., 2003; Chikunya et al., 2004; Kim et al., 2008). The fact that DPA and EPA disappearances were similar would indicate that the higher apparent transfer efficiency of the former into milk (Offer et al., 1999; Toral et al., 2016b) is largely dependent on postruminal FA metabolism. This may involve its endogenous synthesis in body tissues (e.g., through EPA elongation; Miyazaki and Ntambi, 2008) or a more efficient mammary uptake. Based on indirect interspecies comparisons, the apparent transfer efficiency of very long chain n-3 PUFA into milk was considered to be greater in ovines than in bovines (Offer et al., 1999; Loor et al., 2005; Reynolds et al., 2006). Because our results do not indicate interspecies differences in their ruminal disappearance, those in postruminal FA metabolism might be more relevant. Additional in vivo research would be needed to provide further insight into the metabolic fate of these very long chain n-3 PUFA in ruminant tissues.
No clear relationship was found between in vitro disappearance of the incubated PUFA and fermentation, which also challenges the hypothesis of a link between extent of disappearance and toxicity for the microbiota. Nonetheless, a certain association may exist between the effects of PUFA treatments on ruminal $\mathrm{BH}$ and fermentation, with EPA and DHA having a higher influence. In any event, effects on fermentation were generally less severe than those detected on $\mathrm{BH}$, which might be related to the lower number of biohydrogenating bacteria species compared with fibrolytic and proteolytic ones and the ability of the rumen microbiota to adapt to environmental changes (Dehority, 2003; Lourenço et al., 2010). Microorganisms negatively affected by PUFA could have been replaced by strains that were less sensitive to the toxicity of PUFA (Maia et al., 2007). These variations in microbial composition may then explain shifts in molar VFA proportions, in particular the lower acetate:propionate ratio. This is often found in the literature in response to very long chain n-3 PUFA supply, notwithstanding differences in methodologies (in vitro vs. in vivo), ruminant species (cows, sheep, and goats), or basal diet composition (Keady and Mayne, 1999; Fievez et al., 2003; Toral et al., 2016a). Turning to the PCA results, it may be tempting to speculate about certain associations between microorganisms that produce acetate and 18:0, as both acetate and 18:0 seem sensitive to the effects of $\mathrm{C} 20$ and C22 PUFA, in contrast with those involved in alternative $\mathrm{BH}$ pathways and propionate production, which appear to be favored and interrelated.

The trend toward lower gas production and total VFA concentration with EPA and DHA was expected (Toral et al., 2009; Shingfield et al., 2012) given the relatively high PUFA dose (equivalent to the addition of $\sim 3.5-5 \%$ DM of fish oil or marine algae to the diet; Keady and Mayne, 1999; Offer et al., 1999; Boeckaert et al., 2008a). Despite inherent limitations of the in vitro technique, our lack of significant changes in DM and NDF disappearance will contribute to the controversy found in the literature on this subject, with some studies reporting similar results in both cows and ewes (e.g., Keady and Mayne, 1999; Toral et al., 2009) but some others including reductions in fiber degradation (e.g., Fievez et al., 2003; Kim et al., 2008).

\section{CONCLUSIONS}

Overall, EPA and DHA were equally effective for inhibiting the saturation of trans-11 18:1 to 18:0 and had a similar effect on ruminal fermentation in cows and sheep. However, DHA further promoted alternative BH pathways that led to trans-10 18:1 accumulation, and EPA may have had specific effects on 18:3n-3 metabo- 
lism. Minor variations in 18-carbon FA concentrations and rumen fermentation parameters due to DPA suggested a low contribution of this lipid to the ruminal response to marine lipid supply. Most changes due to the 3 PUFA were comparable in bovine and ovine, but there were also relevant specificities (e.g., a stronger inhibition of 18:0 formation in cows and a greater increase in 18:3n-3 intermediate metabolites in sheep), which probably derived from interspecies differences in rumen microbial composition. No direct relationship between in vitro disappearance of the incubated PUFA and effects on $\mathrm{BH}$ (in particular, inhibition of the last step) was found in either cows or ewes, calling into question a putative link between extent of disappearance and toxicity of these PUFA for microbiota. Conversely, an association between the influence of very long chain n-3 PUFA on ruminal lipid metabolism and fermentation may exist in both species. Given the limitations of the in vitro batch cultures of rumen microorganisms, in vivo verification of these findings would be advisable.

\section{ACKNOWLEDGMENTS}

We dedicate this article to the memory of Kevin J. Shingfield, a renowned expert in ruminant lipid metabolism and, above all, a good friend of ours. This work was supported by the Spanish Ministry of Economy and Competitiveness (MINECO; AGL2014-54587-R) and the Spanish National Research Council (CSIC; PIE201540E104). P. G. Toral benefits from a Ramón y Cajal research contract and D. Carreño benefits from an FPI predoctoral grant, both from MINECO. Cofunding by the European Regional Development Fund is also acknowledged.

\section{REFERENCES}

AbuGhazaleh, A. A., L. D. Holmes, B. N. Jacobson, and K. F. Kalscheur. 2006. Short communication: Eicosatrienoic acid and docosatrienoic acid do not promote vaccenic acid accumulation in mixed ruminal cultures. J. Dairy Sci. 89:4336-4339.

AbuGhazaleh, A. A., and T. C. Jenkins. 2004. Disappearance of docosahexaenoic and eicosapentaenoic acids from cultures of mixed ruminal microorganisms. J. Dairy Sci. 87:645-651.

Alizadeh, A. R., M. Alikhani, G. R. Ghorbani, H. R. Rahmani, L. Rashidi, and J. J. Loor. 2012. Effects of feeding roasted safflower seeds (variety IL-111) and fish oil on dry matter intake, performance and milk fatty acid profiles in dairy cattle. J. Anim. Physiol. Anim. Nutr. (Berl.) 96:466-473.

Bernard, L., C. Leroux, and Y. Chilliard. 2013. Expression and nutritional regulation of stearoyl-CoA desaturase genes in the ruminant mammary gland: Relationship with milk fatty acid composition. Pages 161-194 in Stearoyl-CoA Desaturase Genes in Lipid Metabolism. J. M. Ntambi, ed. Springer Science and Business Media, New York, NY.

Boeckaert, C., B. Vlaeminck, J. Dijkstra, A. Issa-Zacharia, T. Van Nespen, W. Van Straalen, and V. Fievez. 2008a. Effect of dietary starch or micro algae supplementation on rumen fermentation and milk fatty acid composition of dairy cows. J. Dairy Sci. 91:47144727.

Boeckaert, C., B. Vlaeminck, V. Fievez, L. Maignien, J. Dijkstra, and N. Boon. 2008b. Accumulation of trans C-18:1 fatty acids in the rumen after dietary algal supplementation is associated with changes in the Butyrivibrio community. Appl. Environ. Microbiol. 74:6923-6930.

Carreño, D., G. Hervás, P. G. Toral, T. Castro-Carrera, and P. Frutos. 2016. Fish oil-induced milk fat depression and associated downregulation of mammary lipogenic genes in dairy ewes. J. Dairy Sci. 99:7971-7981.

Chikunya, S., G. Demirel, M. Enser, J. D. Wood, R. G. Wilkinson, and L. A. Sinclair. 2004. Biohydrogenation of dietary n-3 PUFA and stability of ingested vitamin $\mathrm{E}$ in the rumen, and their effects on microbial activity in sheep. Br. J. Nutr. 91:539-550.

Dehority, B. A. 2003. Rumen Microbiology. Nottingham University Press, Nottingham, United Kingdom.

Dohme, F., V. Fievez, K. Raes, and D. I. Demeyer. 2003. Increasing levels of two different fish oils lower ruminal biohydrogenation of eicosapentaenoic and docosahexaenoic acid in vitro. Anim. Res. 52:309-320.

Fievez, V., F. Dohme, M. Danneels, K. Raes, and D. Demeyer. 2003. Fish oils as potent rumen methane inhibitors and associated effects on rumen fermentation in vitro and in vivo. Anim. Feed Sci. Technol. 104:41-58.

Frutos, P., G. Hervás, F. J. Giráldez, and A. R. Mantecón. 2004. An in vitro study on the ability of polyethylene glycol to inhibit the effect of quebracho tannins and tannic acid on rumen fermentation in sheep, goats, cows, and deer. Aust. J. Agric. Res. 55:1125-1132.

Goering, M. K., and P. J. Van Soest. 1970. Forage Fiber Analysis (Apparatus, Reagents, Procedures, and Some Applications). Agric. Handbook No. 379. USDA Agricultural Research Service, Washington, DC.

Gulati, S. K., J. R. Ashes, and T. W. Scott. 1999. Hydrogenation of eicosapentaenoic and docosahexaenoic acids and their incorporation into milk fat. Anim. Feed Sci. Technol. 79:57-64.

Harvatine, K. J., Y. R. Boisclair, and D. E. Bauman. 2009. Recent advances in the regulation of milk fat synthesis. Animal 3:40-54.

Hervás, G., P. Frutos, F. J. Giráldez, M. J. Mora, B. Fernández, and A. R. Mantecón. 2005. Effect of preservation on fermentative activity of rumen fluid inoculum for in vitro gas production techniques. Anim. Feed Sci. Technol. 123:107-118.

Hudson, J. A., Y. Cai, R. J. Corner, B. Morvan, and K. N. Joblin. 2000. Identification and enumeration of oleic acid and linoleic acid hydrating bacteria in the rumen of sheep and cows. J. Appl. Microbiol. 88:286-292.

INRA (L'Institut National de la Recherche Agronomique). 2007. Alimentation des Bovins, Ovins et Caprins. Besoins des Animaux: Valeur des Aliments. Tables INRA 2007. INRA, Versailles, France.

Jenkins, T. C. 2010. Technical note: Common analytical errors yielding inaccurate results during analysis of fatty acids in feed and digesta samples. J. Dairy Sci. 93:1170-1174.

Kadegowda, A. K. G., M. Bionaz, L. S. Piperova, R. A. Erdman, and J. J. Loor. 2009. Peroxisome proliferator-activated receptorgamma activation and long-chain fatty acids alter lipogenic gene networks in bovine mammary epithelial cells to various extents. J. Dairy Sci. 92:4276-4289.

Kairenius, P., A. Ärölä, H. Leskinen, V. Toivonen, S. Ahvenjärvi, A. Vanhatalo, P. Huhtanen, T. Hurme, J. M. Griinari, and K. J. Shingfield. 2015. Dietary fish oil supplements depress milk fat yield and alter milk fatty acid composition in lactating cows fed grass silage based diets. J. Dairy Sci. 98:5653-5671.

Kairenius, P., V. Toivonen, and K. J. Shingfield. 2011. Identification and ruminal outflow of long-chain fatty acid biohydrogenation intermediates in cows fed diets containing fish oil. Lipids 46:587-606.

Katz, I., and M. Keeney. 1966. Occurrence of ketostearic acids in rumen. J. Dairy Sci. 49:967-970.

Keady, T. W. J., and C. S. Mayne. 1999. The effects of level of fish oil inclusion in the diet on rumen digestion and fermentation parameters in cattle offered grass silage based diets. Anim. Feed Sci. Technol. 81:57-68. 
Kim, E. J., S. A. Huws, M. R. F. Lee, J. D. Wood, S. M. Muetzel, R. J Wallace, and N. D. Scollan. 2008. Fish oil increases the duodenal flow of long chain polyunsaturated fatty acids and trans-11 18:1 and decreases 18:0 in steers via changes in the rumen bacterial community. J. Nutr. 138:889-896.

Lee, M. R. F., J. K. S. Tweed, A. P. Moloney, and N. D. Scollan. 2005. The effects of fish oil supplementation on rumen metabolism and the biohydrogenation of unsaturated fatty acids in beef steers given diets containing sunflower oil. Anim. Sci. 80:361-367.

Lock, A. L., C. Tyburczy, D. A. Dwyer, K. J. Harvatine, F. Destaillats, Z. Mouloungui, L. Candy, and D. E. Bauman. 2007. Trans-10 octadecenoic acid does not reduce milk fat synthesis in dairy cows. J. Nutr. 137:71-76.

Loor, J. J., M. Doreau, J. M. Chardigny, A. Ollier, J. L. Sebedio, and Y. Chilliard. 2005. Effects of ruminal or duodenal supply of fish oil on milk fat secretion and profiles of trans-fatty acids and conjugated linoleic acid isomers in dairy cows fed maize silage. Anim. Feed Sci. Technol. 119:227-246.

Lourenço, M., E. Ramos-Morales, and R. J. Wallace. 2010. The role of microbes in rumen lipolysis and biohydrogenation and their manipulation. Animal 4:1008-1023.

Maia, M. R. G., L. C. Chaudhary, L. Figueres, and R. J. Wallace 2007. Metabolism of polyunsaturated fatty acids and their toxicity to the microflora of the rumen. Antonie van Leeuwenhoek 91:303-314.

Miyazaki, M., and J. M. Ntambi. 2008. Fatty acid desaturation and chain elongation in mammals. Pages 191-211 in Biochemistry of Lipids, Lipoproteins and Membranes. 5th ed. D. E. Vance and J. E. Vance, ed. Elsevier, Oxford, UK.

Morgavi, D. P., H. Boudra, J. P. Jouany, and B. Michalet-Doreau 2004. Effect and stability of gliotoxin, an Aspergillus fumigatus toxin, on in vitro rumen fermentation. Food Addit. Contam. 21:871-878.

Offer, N. W., M. Marsden, J. Dixon, B. K. Speake, and F. E. Thacker. 1999. Effect of dietary fat supplements on levels of $n-3$ poly-unsaturated fatty acids, trans acids and conjugated linoleic acid in bovine milk. Anim. Sci. 69:613-625.

Or-Rashid, M. M., J. K. G. Kramer, M. A. Wood, and B. W. McBride. 2008. Supplemental algal meal alters the ruminal trans-18:1 fatty acid and conjugated linoleic acid composition in cattle. J. Anim. Sci. 86:187-196.

Raphael, W., L. Halbert, G. A. Contreras, and L. M. Sordillo. 2014 Association between polyunsaturated fatty acid-derived oxylipid biosynthesis and leukocyte inflammatory marker expression in periparturient dairy cows. J. Dairy Sci. 97:3615-3625.

Reynolds, C. K., V. L. Cannon, and S. C. Loerch. 2006. Effects of forage source and supplementation with soybean and marine algal oil on milk fatty acid composition of ewes. Anim. Feed Sci. Technol. 131:333-357.

Shingfield, K. J., S. Ahvenjärvi, V. Toivonen, A. Äröla, K. V. V. Nurmela, P. Huhtanen, and J. M. Griinari. 2003. Effect of dietary fish oil on biohydrogenation of fatty acids and milk fatty acid content in cows. Anim. Sci. 77:165-179.
Shingfield, K. J., M. Bonnet, and N. D. Scollan. 2013. Recent developments in altering the fatty acid composition of ruminant-derived foods. Animal 7:132-162.

Shingfield, K. J., P. Kairenius, A. Äröla, D. Paillard, S. Muetzel, S. Ahvenjärvi, A. Vanhatalo, P. Huhtanen, V. Toivonen, J. M. Griinari, and R. J. Wallace. 2012. Dietary fish oil supplements modify ruminal biohydrogenation, alter the flow of fatty acids at the omasum, and induce changes in the ruminal Butyrivibrio population in lactating cows. J. Nutr. 142:1437-1448.

Stamey, J. A., D. M. Shepherd, M. J. De Veth, and B. A. Corl. 2012. Use of algae or algal oil rich in n-3 fatty acids as a feed supplement for dairy cattle. J. Dairy Sci. 95:5269-5275

Toral, P. G., A. Belenguer, P. Frutos, and G. Hervás. 2009. Effect of the supplementation of a high-concentrate diet with sunflower and fish oils on ruminal fermentation in sheep. Small Rumin. Res. $81: 119-125$.

Toral, P. G., A. Belenguer, K. J. Shingfield, G. Hervás, V. Toivonen, and P. Frutos. 2012. Fatty acid composition and bacterial community changes in the rumen fluid of lactating sheep fed sunflower oil plus incremental levels of marine algae. J. Dairy Sci. 95:794-806.

Toral, P. G., L. Bernard, A. Belenguer, J. Rouel, G. Hervás, Y. Chilliard, and P. Frutos. 2016a. Comparison of ruminal lipid metabolism in dairy cows and goats fed diets supplemented with starch, plant oil, or fish oil. J. Dairy Sci. 99:301-316.

Toral, P. G., Y. Chilliard, J. Rouel, H. Leskinen, K. J. Shingfield, and L. Bernard. 2015. Comparison of the nutritional regulation of milk fat secretion and composition in cows and goats. J. Dairy Sci. 98:7277-7297.

Toral, P. G., G. Hervás, D. Carreño, and P. Frutos. 2016b. Does supplemental 18:0 alleviate fish oil-induced milk fat depression in dairy ewes? J. Dairy Sci. 99:1133-1144.

Toral, P. G., G. Hervás, P. Gómez-Cortés, P. Frutos, M. Juárez, and M. A. de la Fuente. 2010a. Milk fatty acid profile and dairy sheep performance in response to diet supplementation with sunflower oil plus incremental levels of marine algae. J. Dairy Sci. 93:1655-1667.

Toral, P. G., K. J. Shingfield, G. Hervás, V. Toivonen, and P. Frutos. 2010b. Effect of fish oil and sunflower oil on rumen fermentation characteristics and fatty acid composition of digesta in ewes fed a high concentrate diet. J. Dairy Sci. 93:4804-4817.

Vahmani, P., A. H. Fredeen, and K. E. Glover. 2013. Effect of supplementation with fish oil or microalgae on fatty acid composition of milk from cows managed in confinement or pasture systems. J. Dairy Sci. 96:6660-6670.

Vlaeminck, B., T. Braeckman, and V. Fievez. 2014. Rumen metabolism of 22:6n-3 in vitro is dependent on its concentration and inoculum size, but less dependent on substrate carbohydrate composition. Lipids 49:517-525.

Wolff, R. L., C. C. Bayard, and R. J. Fabien. 1995. Evaluation of sequential methods for the determination of butterfat fatty acid composition with emphasis on trans-18:1 acids. Application to the study of seasonal variations in French butters. J. Am. Oil Chem. Soc. $72: 1471-1483$ 